\title{
Skin Manifestations of Insulin Resistance: From a Biochemical Stance to a Clinical Diagnosis and Management
}

\author{
Gloria González-Saldivar • René Rodríguez-Gutiérrez • Jorge Ocampo-Candiani • \\ José Gerardo González-González • Minerva Gómez-Flores
}

Received: October 18, 2016 / Published online: December 5, 2016

(C) The Author(s) 2016. This article is published with open access at Springerlink.com

\begin{abstract}
Worldwide, more than 1.9 billion adults are overweight, and around 600 million people suffer from obesity. Similarly, $\sim 382$ million individuals live with diabetes, and $40-50 \%$ of the global population is labeled at "high risk" (i.e., prediabetes). The impact of these two chronic conditions relies not only on the burden of illnesses per se (i.e., associated
\end{abstract}

Enhanced content To view enhanced content for this article go to http://www.medengine.com/Redeem/ 8627F0604A688070.

G. González-Saldivar · J. Ocampo-Candiani ·

M. Gómez-Flores ( $\square$ )

Dermatology Division, Hospital Universitario “Dr. José E. González", Universidad Autónoma de Nuevo León, Monterrey, Mexico

e-mail: minervagomez@meduanl.com

R. Rodríguez-Gutiérrez · J. G. González-González Endocrinology Division, Hospital Universitario “Dr. José E. González", Universidad Autónoma de Nuevo León, Monterrey, Mexico

R. Rodríguez-Gutiérrez

Division of Endocrinology, Diabetes, Metabolism and Nutrition, Department of Medicine, Mayo

Clinic, Rochester, MN, USA

R. Rodríguez-Gutiérrez

Knowledge and Evaluation Research Unit, Mayo

Clinic, Rochester, MN, USA

e-mail: rodriguezgutierrez.rene@mayo.edu increased morbidity and mortality), but also on their increased cost, burden of treatment, and decreased health-related quality of life. For this review a comprehensive search in several databases including PubMed (MEDLINE), Ovid EMBASE, Web of Science, and Scopus was conducted. In both diabetes and obesity, genetic, epigenetic, and environmental factors overlap and are inclusive rather than exclusive. De facto, $70-80 \%$ of the patients with obesity and virtually every patient with type 2 diabetes have insulin resistance. Insulin resistance is a well-known pathophysiologic factor in the development of type 2 diabetes, characteristically appearing years before its diagnosis. The gold standard for insulin resistance diagnosis (the euglycemic insulin clamp) is a complex, invasive, costly, and hence unfeasible test to implement in clinical practice. Likewise, laboratory measures and derived indexes [e.g., homeostasis model assessment of insulin resistance (HOMA-IR-)] are indirect, imprecise, and not highly accurate and reproducible tests. However, skin manifestations of insulin resistance (e.g., acrochordons, acanthosis nigricans, androgenetic alopecia, acne, hirsutism) offer a 
reliable, straightforward, and real-time way to detect insulin resistance. The objective of this review is to aid clinicians in recognizing skin manifestations of insulin resistance. Diagnosing these skin manifestations accurately may cascade positively in the patient's health by triggering an adequate metabolic evaluation, a timely treatment or referral with the ultimate objective of decreasing diabetes and obesity burden, and improving the health and the quality of care for these patients.

Keywords: Acanthosis nigricans; Diabetes; Insulin resistance; Obesity; Skin and insulin resistance

\section{INTRODUCTION}

During the past decades obesity and type 2 diabetes (T2D) epidemics have skyrocketed and have become one of the most important worldwide health care challenges because of their associated morbidity, mortality and decreased health-related quality of life. Despite all the efforts to prevent them, including individual lifestyle strategies (tailored and supervised exercise, healthy diet, and smoking cessation) and novel medications, the prevalence of these two entities continues to increase exponentially. In fact, one study projected that by the year 2050, as much as one-third of the USA and probably the global population will suffer from T2D [1].

A subnormal biologic tissue response to normal insulin concentrations has been called insulin resistance [i.e., the body produces insulin (usually in higher concentrations than in normal subjects) but does not use it effectively] [2]. This is well known as one of the key pathophysiologic factors of type 2 diabetes and usually presents years before the clinical diagnosis of diabetes. Insulin resistance has been suggested to result from an excess of adipose tissue (obesity), which has biochemical effects due to the secretion of multiple cytokines [MCP-1, TNF- $\alpha$, IL-6, IL-18, leptin, resistin, and plasminogen activator inhibitor (PAI)-1, among others], which translates clinically into the metabolic syndrome [3]. The euglycemic insulin clamp is a complex technique considered the gold standard for insulin resistance diagnosis [4]. Given the test's inherent complexity, cost, and lack of realistic implementation in routine clinical practice, several indirect tests have become available in an effort to assess insulin resistance including: abnormal fasting plasma glucose, ratio of triglyceride to high-density lipoprotein, and fasting insulin concentrations. To evaluate insulin resistance, these measures have been used to create indexes such as homeostasis model assessment of insulin resistance (HOMA-IR) and the quantitative insulin sensitivity check index (QUICKI) [4]. Nevertheless, none of these tests are sufficiently reliable and hence are not recommended in day-to-day clinical practice. Skin manifestations of insulin resistance, however, have been described to be reliable and consistent with the euglycemic insulin clamp test results $[5,6]$. Moreover, they offer some key advantages including real-time observation (during physical examination), being non-invasive, non-time consuming, not being burdensome for either patients or clinicians, and involving no increased cost.

Therefore, this review is intended to aid general practice physicians, family doctors, and dermatologists in recognizing the skin manifestations of insulin resistance. This may bring patients at risk of developing T2D to light, consequently triggering an adequate evaluation (including referral) and, if necessary, timely 
treatment. These efforts could help avoid the diabetes/metabolic syndrome burden and increase the quality of the care for these patients.

\section{Compliance with Ethics Guidelines}

This article is based on previously conducted studies and does not involve any new studies of human or animal subjects performed by any of the authors.

\section{Insulin Resistance and its Association with Skin Manifestations}

Insulin is a peptide hormone synthesized and secreted by the beta cells of the pancreas. Glucose is the main regulator of insulin secretion; as the glucose concentration increases, it stimulates insulin secretion. Some of the glucoregulatory effects of insulin are inhibition of glycogenolysis and gluconeogenesis, increased transportation of glucose into adipose tissue and muscle, stimulation of glycogen synthesis, as well as a playing a major role in lipid and protein metabolism $[2,7]$.

As mentioned previously, insulin resistance is defined as reduced responsiveness of a target cell or an organ to the concentration of insulin to which it is exposed: in practice, it refers to the state in which insulin secretion associates with an abnormal glucose response (e.g., impaired glucose tolerance or diabetes) [8]. Four types of insulin resistance have been described: type A, B, C, and secondary causes. Type $\mathrm{A}$ is associated with dysfunction or a decreased number of insulin receptors; type $B$ refers to antibodies against insulin receptors (e.g., leprechaunism with insulin-receptor mutations), and type $\mathrm{C}$ is characterized by post-receptor defects (lipodystrophies). The vast majority of patients, however, have secondary insulin resistance (e.g., impaired glucose tolerance, diabetes, obesity, stress, infection, uremia, acromegaly, glucocorticoid excess, and pregnancy) [9]. Interestingly, around $50 \%$ of the patients with insulin resistance, despite compensatory hyperinsulinemia, present with some degree of hyperglycemia $(>100 \mathrm{mg} / \mathrm{dl})$. Yet, not all patients with hyperinsulinemia and insulin resistance will develop glucose intolerance or diabetes. It is important to acknowledge that virtually every patient with T2D will have insulin resistance years or at least months before the diagnosis of diabetes.

Insulin resistance can present in a wide spectrum of clinical manifestations. These include: acanthosis nigricans, skin tags, hisrutism, (ovarian hyperandrogenism), and androgenetic alopecia (Table 1) [10]. The biologic plausibility of this association relies on the fact that hyperinsulinemia activates insulin growth factor-1 (IGF-1) receptors located in fibroblasts and keratinocytes directly and indirectly, stimulating their proliferation [11, 12]. Hyperinsulinemia can also influence the production of sex steroids. Also, insulin and IGF-1 increase ovarian androgens by stimulating the ovaries to produce androgens via the increase of 17-hydroxylase local activity and inhibiting hepatic synthesis of sex hormone-binding globulin (SHBG), which increases the availability of free testosterone [11, 12]. It is also important to mention that skin diseases such as psoriasis, hidradenitis suppurativa, and vitiligo have been strongly associated with insulin resistance and metabolic syndrome [4].

\section{Obesity and T2D. Why Are They \\ Important?}

The prevalence of obesity and T2D continues to increase despite multiple efforts, and today 
both seem to be unstoppable tsunamis. In 2014, more than 1.9 billion adults were overweight and more than 600 million were obese. At the same time, over 380 million people in the world suffer from diabetes, and $35-50 \%$ of the global population ( $>3.0$ billion) is at high risk of developing it-the so-called prediabetes, which in all cases is accompanied by insulin resistance. The impact of these two conditions relies not only on the burden of illness per se, but even more on its associated increased cardiovascular risk, musculoskeletal disorders, cost, mortality, burden of treatment, and decreased quality of life. Both entities are influenced by genetic, epigenetic, and environmental factors. The latter includes sedentary lifestyle, unhealthy dietary choices, and low socioeconomic status, among others [10]. In addition, obesity is considered the most common comorbidity and risk factor for diabetes, as $80 \%$ of patients with diabetes are overweight or obese. Interestingly, $70-80 \%$ of the patients with obesity will develop insulin resistance.

It is important to acknowledge that obesity and T2D are associated with a considerable number of dermatoses, including acanthosis nigricans, acrochordons, hirsutism, and keratosis pilaris, among others [10]. Specifically in patients with diabetes, at least one-third will present some type of skin manifestation during the course of their disease [13]. A recent study reported that $91 \%$ of patients with diabetes have at least one dermatologic manifestation [13]. Hence, all of these skin conditions should alert physicians to further study the metabolic characteristics of these individuals, which can result in a prompt diagnosis and if necessary provide treatment.

\section{Skin Manifestations of Insulin Resistance}

\section{Acrochordons}

Acrochordons, also known as fibroepithelial polyps, skin tags, or soft fibromas, are among the most common skin tumors [14]. They are a benign skin condition unusual before age 30 years, but highly prevalent thereafter, particularly in advanced age. In fact, after age 40 , the frequency of skin tags is $\sim 37 \%$ [11]. They are more common among women and overweight or obese patients; however, these also have a familial/genetic relationship. Recently, several studies have associated acrochordons to impaired glucose tolerance and diabetes [15-18]. In 1976, Margolis et al. conducted one of the first studies and reported that $9.4 \%$ of 500 hospitalized patients had acrochordons, of which $72 \%$ had $\mathrm{T} 2 \mathrm{D}$, and suggested that acrochordons could be a risk factor for diabetes [19]. Later, in the late 1980s, Norris et al. reported a correlation between skin tags and insulin resistance (61\% of their studied population had hyperinsulinemia) for the first time. Interestingly, only $15 \%$ of the individuals had a corresponding impaired fasting glucose. Strengthening the association, a study performed by Kahana et al. revealed that 34\% of patients with acrochordons had T2D [20].

The pathophysiologic mechanism by which hyperinsulinemia is related to acrochordons remains open to debate. Insulin, however, is a well-recognized growth-promoting hormone, and hyperinsulinemia has been directly correlated with IFG-1 and decreased insulin-like growth factor-binding protein 3 (IGFBP-3). IGF-1 binds to receptors in keratinocytes, triggering epidermal hyperplasia, and the reduction in IGFBP-3 may decrease the transcription of normally activated 
anti-proliferative genes. These endocrine disturbances alter cellular proliferation, eventually becoming clinically evident as skin tags [12].

Clinically, these lesions are small, soft, slightly hyperpigmented tumors of variable size and characteristically pedunculated (see Fig. 1). Acrochordons are frequently multiple, but can appear as a single lesion. Intertriginous sites such as the neck, axillae and groin are the most common areas of presentation; however, they can appear in other areas such as the eyelids and inframammary creases [16, 18, 21]. Typically these skin lesions are completely asymptomatic and may become painful because of irritation [22]. Differential diagnoses include melanocytic nevi, neurofibromas, and pedunculated seborrheic keratosis; conditions associated with skin tags include Gardner syndrome, Birt-Hogg-Dubé syndrome, and tuberous sclerosis, among others $[18,23]$.

Histopathology reveals a papillomatous architecture with normal or acanthotic epidermis, surrounding fibrovascular tissue composed of loose to dense collagen fibers, and numerous thin-walled dilated capillaries; in large, pedunculated lesions, adipocytes can be observed in the center of the tumor $[23,24]$ (see Fig. 2). Diagnosis is usually made clinically;

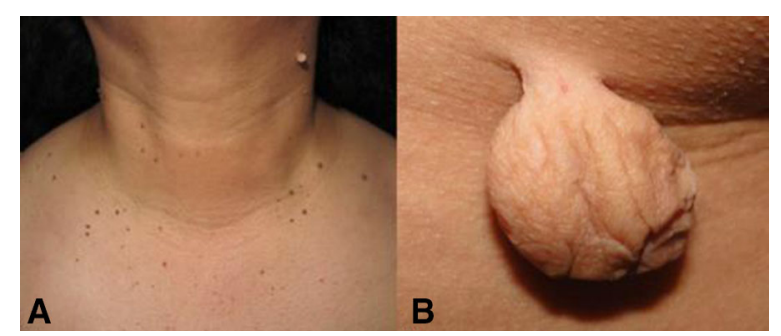

Fig. 1 a Classical presentation of acrochordons, showing multiple, pedunculated and small tumors, some of them slightly hyperpigmented. b Giant acrochordon, soft, skin-colored, round, pedunculated tumor

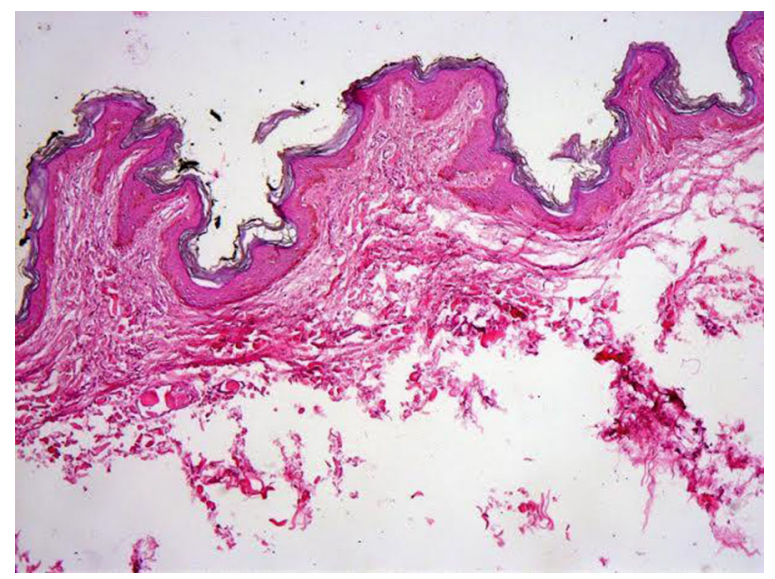

Fig. 2 Histopathology of an acrochordons demonstrating papillomatosis, slight acanthosis, and fibrovascular tissue in papillary dermis (hematoxylin and eosin, original magnification $\times 40$ )

nonetheless, atypical cases can present because of macroscopic morphology or unusual topography; excision of the lesion and histopathology can confirm the diagnosis.

Treatment is more of a cosmetic than a clinical concern, and various methods are currently used. Electrosurgery and cryotherapy are among the most commonly used methods, yet a challenge of this technique is the difficulty of limiting the freezing zone exclusively to the soft fibroma [25]. Flat tweezers can be used instead, dipping them in the liquid nitrogen and grasping the skin tags with the cooled metal [25]. However, the most direct and simple approach is to simply excise them with sharp and good-quality scissors at the level of the surrounding skin. Lesions with a wide base might require local anesthesia; ferric subsulfate and aluminum chloride can be used for hemostasis (Table 1).

\section{Acanthosis Nigricans}

Acanthosis nigricans (AN) is a common cutaneous finding characterized by velvety, hyperpigmented plaques and is usually related to conditions associated with insulin resistance 
Table 1 Skin manifestations of insulin resistance

\begin{tabular}{|c|c|c|c|c|}
\hline & Topography & Clinical manifestations & Histopathology & Treatment \\
\hline Acrochordons & $\begin{array}{l}\text { Intertriginous } \\
\text { areas (neck, } \\
\text { axillae, and } \\
\text { groin) }\end{array}$ & $\begin{array}{l}\text { Soft, pedunculated papules, } \\
\text { skin colored or slightly } \\
\text { hyperpigmented }\end{array}$ & $\begin{array}{l}\text { Papillomatosis, acanthosis, } \\
\text { surrounding fibrovascular } \\
\text { tissue (collagen fibers and } \\
\text { thin-walled dilated capillaries) }\end{array}$ & $\begin{array}{l}\text { Excision, } \\
\text { electrosurgery, } \\
\text { cryotherapy }\end{array}$ \\
\hline $\begin{array}{l}\text { Acanthosis } \\
\text { nigricans }\end{array}$ & $\begin{array}{l}\text { Knuckles, } \\
\text { intertriginous } \\
\text { areas (neck, } \\
\text { axillae, elbows, } \\
\text { groin) }\end{array}$ & $\begin{array}{l}\text { Symmetrical, velvety, light } \\
\text { brown to black thickened } \\
\text { plaques and accentuation } \\
\text { of skin marks }\end{array}$ & $\begin{array}{l}\text { Hyperkeratosis, acanthosis, and } \\
\text { papillomatosis }\end{array}$ & $\begin{array}{l}\text { Lifestyle changes, oral } \\
\text { or topical retinoids, } \\
\text { ammonium lactate, } \\
\text { lactic acid }\end{array}$ \\
\hline $\begin{array}{l}\text { Androgenetic } \\
\text { alopecia }\end{array}$ & $\begin{array}{l}\text { Scalp-bitemporal } \\
\text { recession and } \\
\text { vertex }\end{array}$ & $\begin{array}{l}\text { Progressive diffuse thinning } \\
\text { of hair leading to bald } \\
\text { patch }\end{array}$ & $\begin{array}{l}\text { Replacement of terminal hairs } \\
\text { by vellus hairs, increased } \\
\text { telogen:anagen ratio }\end{array}$ & $\begin{array}{l}\text { Oral finasteride, } \\
\text { dutasteride, topical } \\
\text { minoxidil } 2 \% \text { and } \\
5 \%\end{array}$ \\
\hline
\end{tabular}

(e.g., T2D and obesity). However, in rare cases it may develop as a sign of internal malignancy (e.g., aggressive adenocarcinomas of the gastrointestinal tract) [26-28]. AN was first described by Pollitzer and Janovsky in 1889 in two patients who presented with "widespread pigmentation and papillary hypertrophy" $[29,30]$.

AN is classified according to its etiology in eight types: benign, obesity-associated, syndromic, malignant, acral, unilateral, drug-induced, and mixed [26]. Benign AN is usually congenital or develops during early childhood and may be inherited as an autosomal dominant trait. Obesity-associated $\mathrm{AN}$, also known as "pseudo-AN," is the most common cause of AN worldwide and develops as an expression of insulin resistance. Syndromic AN includes type A and B insulin resistance syndromes (e.g., Berardinelli-Seip syndrome, Lawrence syndrome), Crouzon's syndrome, and multiple other rare syndromic disorders. Malignant AN is most frequently associated with gastrointestinal tract adenocarcinomas; it is severe, abrupt, exuberant, and generally involves the mucous membranes. Nicotinic acid is the most recognized medication that causes $\mathrm{AN}$, although others have been described such as oral contraceptives, heroin, fusidic acid, hydantoin-like derivates, corticosteroids, and methyltestosterone. In these cases, AN typically resolves spontaneously within 4-11 months after stopping the medication [26]. Another classification is a quantitative scale developed by Burke et al. [31]. In this classification the presence or absence of $\mathrm{AN}$ in the neck and axillae is graded from 0 to 4 . In addition, the skin texture of the neck is taken into consideration and classified into smooth, rough, coarse, or extremely coarse. AN in the knuckles, elbows, and knees is only documented as present or absent [31]. Although the authors establish this classification as easy with good reproducibility, it is not a practical tool for day-to-day clinical practice.

Inconsistent data exist with regard to the real prevalence of AN as it varies widely depending on the age, ethnicity, skin phototype, and 
anthropometric characteristics, among others [32-34]. Quaiser et al., in a study involving 675 adolescents, found an overall AN prevalence of $18.9 \%$. A significant association was linked to their ethnicity, and AN prevalence was higher in obese students when compared with normal BMI students (49.2\% vs. $7.7 \%$ ) [6]. In a study conducted by our research group with 703 Latino students between 17 and 24 years, a prevalence of AN of $47.8 \%$ in any site, including the knuckles, elbows, neck, and axillae was found [32]. In addition, AN has been reported as a clinical manifestation in $\sim 50 \%$ of the patients with Down syndrome, which are also prone to obesity, metabolic syndrome, and diabetes [35].

The pathogenesis is similar to that of acrochordons and results from growth factor stimulation of keratinocytes and fibroblasts in the dermis. The tyrosine kinase receptor family includes insulin, IGF, epidermal growth factor, and fibroblast growth factor receptors, among others. An increase in the insulin concentration translates into keratinocyte and fibroblast proliferation due to stimulation of IGF-1 receptors $[9,11,26]$.

Clinically AN is characterized by symmetrical, velvety, light brown to black thickened plaques with accentuation of skin marks, typically located in intertriginous areas $[5,9,26,33,36]$. The classic topography includes the neck, axillae, and elbows (see Figs. 3 , 4). Involvement of other sites, however, has been described (e.g., periorbital and periumbilical areas, thighs, inframammary folds, knees) $[5,6,9,26,33$, $36,37]$. In fact, one of the studies conducted by our research group revealed that the site with the highest prevalence of $\mathrm{AN}$, even in subjects with normal BMI, was the knuckles [32]. Although AN is stereotypically asymptomatic, it can rarely be pruritic [38].

Histopathologic changes are subtle and consist of hyperkeratosis, acanthosis, and mild

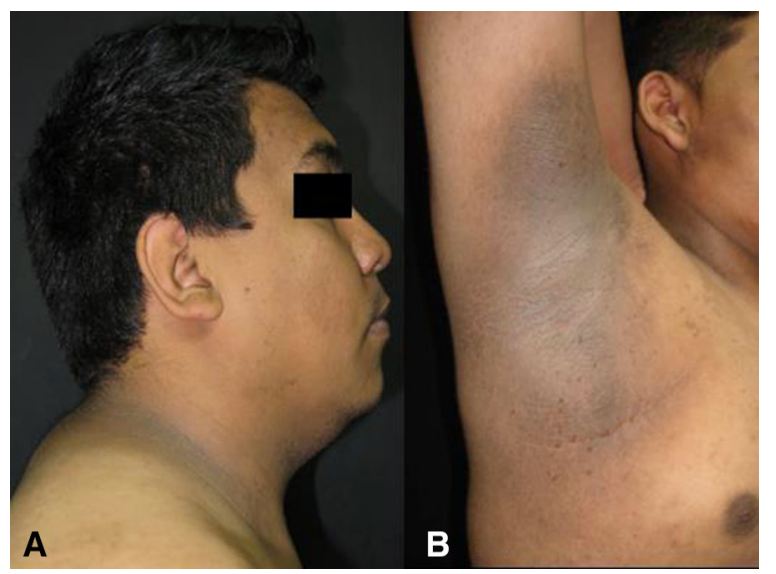

Fig. 3 Acanthosis nigricans in the neck (a) and axillae (b). Characteristic hyperpigmented, thickened, brown plaques with a velvety and smooth appearance in a male patient

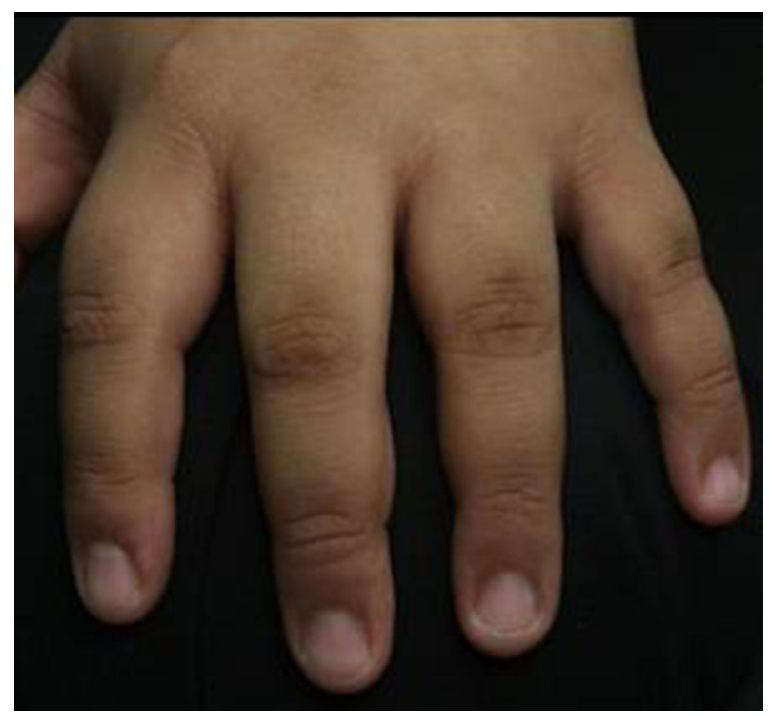

Fig. 4 Acanthosis nigricans in the proximal and distal interphalangeal joints in a healthy male patient

papillomatosis (see Fig. 5). The dermis is usually normal, but can present with elongated dermal projections [38]. One study demonstrated that the most frequent finding was hyperkeratosis in $100 \%$, followed by papillomatosis in $90 \%$ of biopsies; a less frequent finding was irregular acanthosis in $26.6 \%$ of biopsies [38]. The brownish color of this dermatosis is due to the thickening of the stratum corneum; however, a silver nitrate stain can sometimes show melanin 


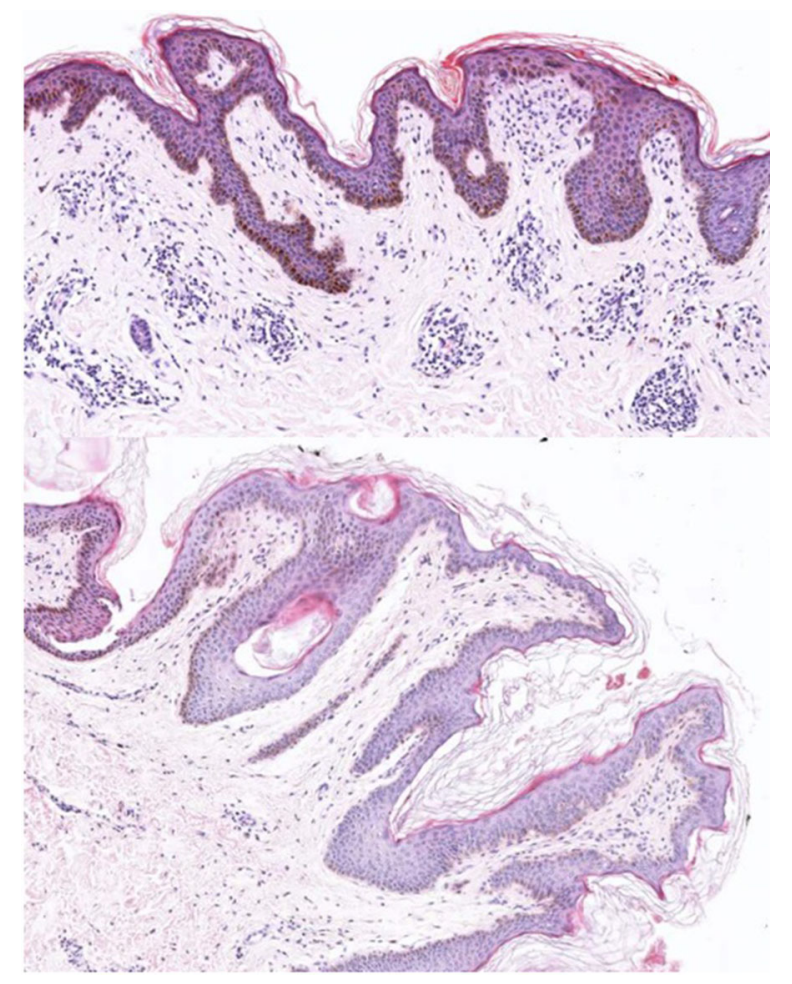

Fig. 5 Biopsy from the neck of a patient with acanthosis nigricans, showing histological features of orthokeratotic hyperkeratosis, mild acanthosis, and papillomatosis (hematoxylin and eosin, original magnification $\times 40$ )

deposition in the basal layer of the epidermis [37].

The first step in the evaluation of $\mathrm{AN}$ is to determine its etiology. Relevant information includes: the age, time of onset, evolution, anthropometric measures, family history of metabolic syndrome, medications, and data related to diabetic syndrome (e.g., polyuria, polydipsia, polyphagia, weight loss) or other symptoms suggestive of internal malignancy. In this sense, it is recommended that all overweight or obese patients are screened for abnormal fasting glucose and/or liver function tests. For must cases (obesity-induced $\mathrm{AN}$ ), weight loss and exercise should be recommended as the first-line therapy (i.e., by increasing insulin sensitivity and reducing insulin resistance) [26, 39]. Some authors, however, have reported the use of oral or topical retinoids (probably regulating the proliferation and differentiation of keratinocytes) as effective treatments $[26,40,41]$. In a recent case report, a Hispanic female was effectively treated with a triple combination (tretinoin $0.05 \%$, hydroquinone $4 \%$, and fluocinolone acetonide $0.01 \%$ ) [42]. Other employed agents are acitretin, ammonium lactate, lactic acid, trichloroacetic acid peelings, and urea, with variable response $[39,43]$.

\section{Androgenetic Alopecia}

Androgenetic alopecia (AGA) is the most common subtype of the non-scarring alopecias. AGA is an androgen-dependent, hereditary physical trait that results from the conversion of scalp terminal hairs into miniaturized vellus hairs in a characteristic pattern [44]. It affects men and women at a similar rate in all populations, but has been reported to have a higher prevalence among Caucasians, usually presenting in late adolescence [45-47]. Epidemiological data show that by age 30 nearly one-third of men will develop AGA. This percentage increases with age (i.e., $\sim 50 \%$ by age 50 ) [48]. The risk of developing AGA depends on several factors, including family history and genetic factors. Other related factors are tobacco use, benign prostatic hyperplasia, and prostatic cancer. Paradoxically, one of the most common factors was just recently described-the metabolic syndrome (i.e., insulin resistance) $[45,48]$. Recently, Nabaie et al. reported a no significant relationship between androgenetic alopecia and insulin resistance in a case-control study; however, others have argued that early androgenetic alopecia is a marker of insulin resistance $[49,50]$. Hence, the association, while plausible, remains open to debate. The most 
accepted classification/grading system for men is the Norwood-Hamilton classification and the Ludwig scale for women [51].

Dihydrotestosterone (DHT) is the key androgen involved in the pathogenesis of AGA. Testosterone is metabolized in many skin tissues; it penetrates the cell membrane and is irreversibly converted by 5-alpha reductase (mainly type II) in the cytoplasm into its most potent form: DHT. The 5-alpha reductase enzyme has two isotypes, type I and II $[44,52]$. Type I is present predominantly in the sebaceous glands, follicular keratinocytes, sweat glands and liver; type II dominates in outer root sheath of hair follicles of the scalp, beard, and chest [44]. DHT binds to androgen receptors and is translocated to the nucleus, where it stimulates gene transcription. This activation is key as it has been shown to be the responsible for the gradual transformation of terminal follicles into smaller vellus hairs, with a shortened anagen phase [51, 53]. In a case-control study in young males with and without AGA, González-González et al. evaluated different measures of insulin resistance in this population. The HOMA-IR index and free testosterone levels were significantly higher in cases when compared to controls [45]. Similarly, Bakry et al. described 100 males with AGA and suggested that patients with stage III or higher should be considered for metabolic syndrome and insulin resistance assessment [54]. More recently, a systematic review, which included 31 studies and 50,956 individuals $(29,254$ with AGA), revealed these patients were at an increased risk of coronary heart disease, hypertension, insulin resistance, and dyslipidemia [55].

Clinically, the hair loss pattern in AGA in men usually starts with bitemporal recession of the frontal hairline as well as diffuse thinning of hair in the vertex (see Fig. 6). Complete hair loss

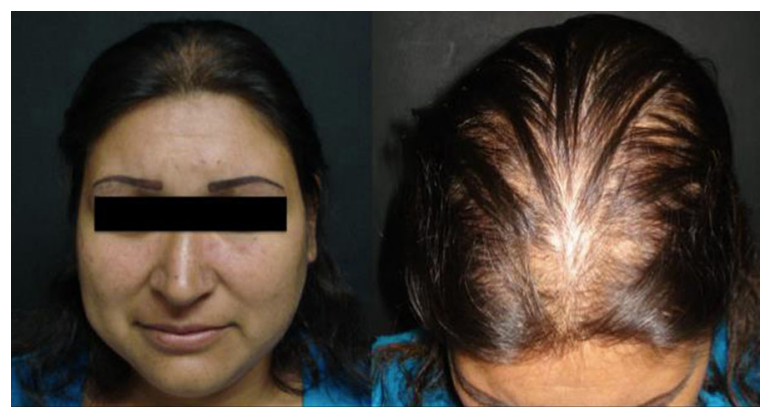

Fig. 6 Female pattern androgenetic alopecia. Thinning limited to the crown region; notice there is no affection of the frontal hairline

centrally on the vertex comes afterwards, producing a bald patch, which gradually expands, joining the receding frontal hairline. Hair loss usually starts after puberty, and the progression rate is quite variable [56]. This type of alopecia is usually progressive, symmetrical, and asymptomatic. Less frequently, men can develop diffuse thinning of the crown while preserving the frontal hairline, resembling the female pattern [46]. On the other hand, in women AGA typically presents as a diffuse reduction in hair density over the frontal and central areas, although the parietal and occipital regions may also be affected [46] (see Fig. 6). A complete history should include the age, sex, smoking habits, clinical hair loss course, family history, accompanying symptoms associated with the hair loss, previous treatments, and use of medications (e.g., anabolic steroids). In women, a profound gynecological history is mandatory including menarche, the menstrual cycle, amenorrhea, menopause, the use systemic hormone treatment, impaired fertility, and signs of hyperandrogenism.

Dermatological examination should include not only the scalp, but also the body hair distribution, skin, and nails as well [46]. The scalp is usually normal, but concomitant seborrheic dermatitis is a common finding. If 
the patient has perifollicular erythema and/or inflammation, other diagnoses should be considered and ruled out. In subjects with AGA, a complete physical examination is particularly important since other diseases such as coronary artery disease and metabolic syndrome have been strongly associated [45, 47, 48, 54, 55, 57]. A pull-test should always be performed in the right and left parietal, frontal, and occipital areas as well as in clinically affected areas. This test, however, is positive only in subjects in the active phase of AGA when a diffuse positive test is present. According to the clinical scenario, measuring thyroid-stimulating hormone, iron, and androgen levels can be considered with the intent to rule out other causes of alopecia [47].

Dermatoscopy is quite useful in the diagnosis of AGA. The classical dermatoscopic sign is the diversity in hair diameter of more than 20\% (anisotrichosis) with vellus hairs (see Fig. 7). A brownish depressed halo at the follicular openings is also common (peripilar sign). Advanced cases can show yellow dots,

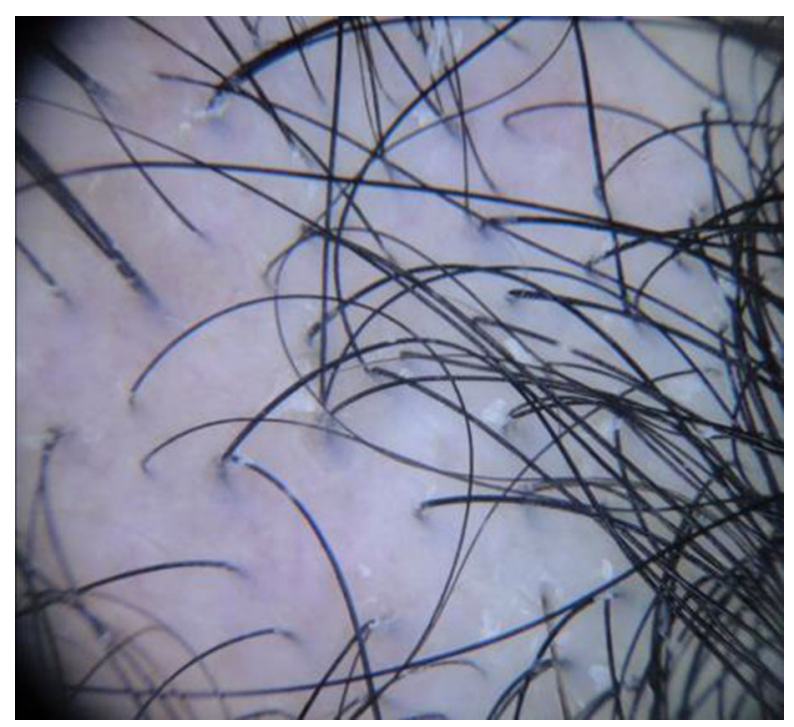

Fig. 7 Dermoscopy of androgenetic alopecia. Anisotrichosis, miniaturization of hair follicles, and single hair follicular units reflecting sebum and keratin accumulation in the dilated follicular infundibula $[52,58]$. In cases where the diagnosis is unclear, ideally two punch biopsies of not less than $4 \mathrm{~mm}$ in diameter should be taken, always following the direction of the hair shafts and deep into the subcutaneous fat, where anagen hair bulbs are normally located. The preferred site of biopsy is the central scalp in an area that is clinically representative of the hair loss. Biopsies should never be taken from the bitemporal area since miniaturized hairs may exist independently of AGA [46, 47]. Histopathology reveals replacement of terminal hairs by secondary vellus hairs as well as an increased ratio of telogen to anagen hairs. Sometimes there can be a perifollicular lymphohistiocytic infiltrate around the infundibulum, which is a non-specific finding [56].

General recommendations in the treatment of AGA include an adequate diet, avoiding hair care products that could worsen the hair loss process, discontinuing medications that could negatively affect hair growth (e.g., retinoids, cytotoxic agents, anticoagulants), and treating any underlying local or systemic disease (e.g., hypothyroidism, anemia, seborrheic dermatitis, psoriasis) [47, 51, 56]. Cosmetic treatment consists of tinted powers, lotions, hair sprays, or wigs. Medical treatment includes oral finasteride, dutasteride, and topical $2 \%$ and $5 \%$ minoxidil, which is important to use for at least 1 year before discarding its effectiveness. Hair restoration surgeries involve hair transplantation, scalp reduction surgery, or a combination [47, 59]. It is important to mention that AGA produces moderate psychological stress in most men, and for a predisposed subgroup this may result in an unwanted reduction in the quality of life and even become a major focus of body dysmorphic concern [60]. 
Hirsutism, Acne, and Menstrual Irregularities

Polycystic ovary syndrome (PCOS) is a well-recognized metabolic and reproductive entity that increases the risk of developing T2D and infertility [61]. The term "diabète des femmes á barbe" (diabetes of bearded woman) was used for the first time by Archard and Thiers in the 1920s, establishing the first association of impaired glucose metabolism and hyperandrogenism [62]. Independent of obesity, women with PCOS have insulin resistance. The prevalence of obesity varies between $25 \%$ and $70 \%$ (usually central) and contributes to insulin resistance [63]. In vitro studies have revealed that insulin increases the effect of LH on ovarian production of androgens [64]. Hyperandrogenism is one of the key diagnostic features of PCOS and manifests clinically as hirsutism, acne, and/or AGA [65].

Hirsutism per se refers to an excess of terminal body hair in a male pattern, including the lower abdomen, linea alba, periareolar area, chin, and upper lip in women. It affects between $5 \%$ and $10 \%$ of premenopausal women, most of the cases being secondary to PCOS [66]. The activity of the enzyme 5-alpha reductase is enhanced in hair follicles and is stimulated by androgens, IGF, and insulin to convert testosterone into dihydrotestosterone, stimulating hair growth [65]. The most common method for evaluating hirsutism is through the Ferriman and Gallwey scale [67]. Differential diagnoses include hypertrichosis, which is generalized hair growth, medications such as glucocorticoids or cyclosporine, congenital adrenal hyperplasia, Cushing's syndrome, androgen-secreting tumors, and thyroid dysfunction [68]. Treatment modalities include lifestyle modifications and mechanical and medical therapies [69]. Lifestyle changes should include clean eating habits, exercise, and weight loss. Bleaching, shaving, waxing, and laser hair removal are definitively useful but may be painful and expensive. Medical treatment includes oral contraceptives, gonadotropin-realizing hormone agonists, insulin-sensitizing agents such as metformin, or drugs with antiandrogenic effects such as cyproterone acetate, eflornithine, and spironolactone [69, 70].

Acne is another clinical feature of insulin resistance-hyperandrogenemia in PCOS and co-exists in 15-25\% of women with PCOS [71]. Patients with acne often exhibit increased levels of serum glucose and insulin as well as insulin resistance, and its association has been long recognized [72]. Interestingly, in patients with acne vulgaris, desnutrin, also called adipose triglyceride lipase (ATGL), has been found to be low and to have a positive correlation with insulin and HOMA-IR values [73]. In this patient hyperandrogenemia promoted comedone production by increasing the size of the sebaceous glands and therefore increased sebum production and produced abnormal follicular keratinization [65]. Exaggerated expression of mechanistic target of rapamycin (mTOR), fueled by the Western diet, is increased in patients with acne. However, this association, mediated by conserved serine/ threonine kinase (mTORC1), has been found to be present even in the absence of metabolic disease or insulin resistance and emerges as a determinant factor in the appearance of acne [74]. Acne appears clinically as inflammatory lesions on the mandibular area, neck, chest, and upper back. Management should include lifestyle changes such as nutrition and exercise. In fact, a small reduction of body weight $(2-5 \%)$ has been demonstrated to produce clinical benefits $[75,76]$. Topical treatment includes retinoids and benzoyl peroxide. Alternatively, systemic treatments 
include oral contraceptives (cyproterone acetate or drospirenone), spironolactone and systemic antibiotics (e.g., minocycline, doxycycline, azithromycin), and, in selected refractory cases, isotretinoin [76].

\section{CONCLUSION}

Insulin resistance is a hallmark biochemical feature of both obesity and diabetes. It is one of the key underlying pathophysiological mechanisms of the latter and appears years before its clinical diagnosis. Its accurate and feasible diagnosis is complex and invasive. Indirect laboratory measures and indexes are imprecise and unreliable. Skin manifestations of insulin resistance offer, however, a reliable and easy way to detect insulin resistance. Clinicians should always recall that skin conditions of insulin resistance might reflect an underlying metabolic imbalance causing the patient to be at risk or of already have diabetes. At the same time, clinicians should not only recognize them, but act by assessing the patients' current metabolic status and, if necessary, counseling them with regard to lifestyle interventions such as healthy food, exercise, non-smoking, and weight loss.

\section{ACKNOWLEDGEMENTS}

No funding or sponsorship was received for this study or publication of this article. We would like to thank Sergio Lozano-Rodriguez, MD, from the Office of the Vice Dean of Research of the "Dr. Jose E. Gonzalez" University Hospital, for the critical reading of the manuscript. All named authors meet the International Committee of Medical Journal Editors (ICMJE) criteria for authorship for this manuscript, take responsibility for the integrity of the work as a whole, and have given final approval for the version to be published.

Disclosures. Gloria González-Saldivar, René Rodríguez-Gutiérrez, Jorge Ocampo-Candiani, José Gerardo González-González, and Minerva Gómez-Flores declare no disclosures or conflicts of interest.

Compliance with Ethics Guidelines. This article is based on previously conducted studies and does not involve any new studies of human or animal subjects performed by any of the authors.

Data Availability. Data sharing is not applicable to this article as no data sets were generated or analyzed during the current study.

Open Access. This article is distributed under the terms of the Creative Commons Attribution-NonCommercial 4.0 International License (http://creativecommons.org/licenses/ by-nc/4.0/), which permits any noncommercial use, distribution, and reproduction in any medium, provided you give appropriate credit to the original author(s) and the source, provide a link to the Creative Commons license, and indicate if changes were made.

\section{REFERENCES}

1. Boyle J, Thompson T, Gregg E, Barker L, Williamson D. Projection of the year 2050 burden of diabetes in the US adult population: dynamic modeling of incidence, mortality, and prediabetes prevalence. Popul Health Metr. 2010;8:1.

2. Moller DE, Flier JS. Insulin resistancemechanisms, syndromes, and implications. N Engl J Med. 1991;325:938-48.

3. Jung U, Choi M-S. Obesity and its metabolic complications: the role of adipokines and the relationship between obesity, inflammation, 
insulin resistance, dyslipidemia and nonalcoholic fatty liver disease. Int J Mol Sci. 2014;15:6184-223.

4. Napolitano M, Megna M, Monfrecola G. Insulin resistance and skin diseases. Sci World J. 2015. doi:10.1159/000245731.

5. Yamazaki H, Ito S, Yoshida H. Acanthosis nigricans is a reliable cutaneous marker of insulin resistance in obese Japanese children. Pediatr Int. 2003;45:701-5.

6. Mukhtar Q, Cleverley G, Voorhees RE, McGrath JW. Prevalence of acanthosis nigricans and its association with hyperinsulinemia in New Mexico adolescents. J Adolesc Health. 2001;28:372-6.

7. Edgerton DS, et al. Insulin' s direct effects on the liver dominate the control of hepatic glucose production. J Clin Invest. 2006;116:521-7.

8. Shanik $\mathrm{MH}$, et al. Insulin resistance and hyperinsulinemia: Is hyperinsulinemia the cart or the horse? Diabet Care. 2008;31:262-8.

9. Hermanns-Lê T, Scheen A, Piérard GE. Acanthosis nigricans associated with insulin resistance. Am J Clon Dermatol. 2004;5:199-203.

10. Yosipovitch G, DeVore A, Dawn A. Obesity and the skin: skin physiology and skin manifestations of obesity. J Am Acad Dermatol. 2007;56:901-16.

11. Barbato M, et al. Association of acanthosis nigricans and skin tags with insulin resistance. An Bras Dermatol. 2012;87:97-104.

12. Cordain L, Eades MR, Eades MD. Hyperinsulinemic diseases of civilization: more than just Syndrome X. Comp Biochem Physiol A Mol Integr Physiol. 2003;136:95-112.

13. Murphy-Chutorian B, Han G, Cohen SR. Dermatologic manifestations of diabetes mellitus. a review. Endocrinol Metab Clin N Am. 2013;42:869-98.

14. El Safoury OS, Ibrahim M. A clinical evaluation of skin tags in relation to obesity, type 2 diabetis mellitus, age, and sex. Indian J Dermatol. 2011;56:393-7.

15. Sari R, Akman A, Alpsoy E, Balci MK. The metabolic profile in patients with skin tags. Clin Exp Med. 2010;10:193-7.

16. Rasi A, Soltani-Arabshahi R, Shahbazi N. Skin tag as a cutaneous marker for impaired carbohydrate metabolism: a case-control study. Int J Dermatol. 2007;46:1155-9.
17. Demir S, Demir Y. Acrochordon and impaired carbohydrate metabolism. Acta Diabetol. 2002;39:57-9.

18. Schilling WH, Crook MA. Cutaneous stigmata associated with insulin resistance and increased cardiovascular risk. Int J Dermatol. 2014;53:1062-9.

19. Margolis J, Margolis LS. Skin tags-a frequent sign of diabetes mellitus. N Engl J Med. 1976;294:1184.

20. Kahana M, et al. Skin tags: a cutaneous marker for diabetes mellitus. Acta Derm Venereol. 1987;67:175-7.

21. Behm B, Schreml S, Landthaler M, Babilas P. Skin signs in diabetes mellitus. J Eur Acad Dermatol Venereol. 2012;26:1203-11.

22. Men J, Boberg J. Fibroepithelial polyps. An unusual case report. J Am Podiatr Med Assoc. 1990;80:496-8.

23. Kamino H, Reddy VB, Pui J. Dermatology. Philadelphia: Elsevier; 2012. p. 1961.

24. Brinster NK, Liu V, Diwan AH, McKee PH. Dermatopathology: high-yield pathology. Edinburgh: Elsevier; 2011. p. 446.

25. Pfenninger JL. Pfenninger and Fowler's Procedures for Primary Care. Philadelphia: Elsevier; 2011. p. 69-84.

26. Sinha S, Schwartz RA. Juvenile acanthosis nigricans. J Am Acad Dermatol. 2007;57:502-8.

27. Dobrev D. Case of acanthosis nigricans associated with gastric cancer. Suvr Med. 1958;9:100-3.

28. Lindewall G. Acanthosis nigricans associated with carcinoma of the stomach: a case report. Acta Derm Venereol. 1960;40:493-9.

29. Pollitzer S. Acanthosis nigricans: a symptom of a disorder of the abdominal sympathetic. JAMA. 1909;53:1369-73.

30. Janovsky V. Acanthosis nigricans. In: Unna PG, Morris M, Besnier E, editors. International atlas of rare skin diseases. London: HK Lewis \& Co; 1891. p. 4-5.

31. Burke JP, Hale DE, Hazuda HP, Stern MP. A quantitative scale of acanthosis nigricans. Diabet Care. 1999;22:1655-9.

32. Gómez-Flores $\mathrm{M}$, et al. Implications of a clinically ignored site of acanthosis nigricans: the knuckles. Exp Clin Endocrinol Diabet. 2014;123:27-33. 
33. Kluczynik C, et al. Acanthosis nigricans and insulin resistance in overweight children and adolescents. An Bras Dermatol. 2012;87:531-7.

34. Stuart CA, Pate CJ, Peters EJ. Prevalence of acanthosis nigricans in an unselected population. Am J Med. 1989;87:269-72.

35. Muñoz-Pérez MA, Camacho F. Acanthosis nigricans: a new cutaneous sign in severe atopic dermatitis and Down syndrome. J Eur Acad Dermatol Venereol. 2001;15:325-7.

36. Kong AS, et al. Acanthosis nigricans and diabetes risk factors: prevalence in young persons seen in Southwestern US primary care practices. Ann Fam Med. 2007;5:202-8.

37. Matsuoka LY, Wortsman J, Goldman J. Acanthosis Nigricans. Clin Dermatol. 1993;11:21-5.

38. Puri N. A study of pathogenesis of acanthosis nigricans and its clinical implications. Indian J Dermatol. 2011;56:678-83.

39. Phiske MM. An approach to acanthosis nigricans. Indian Dermatol Online J. 2014;5:239-49.

40. Darmstadt GL, Yokel BK, Horn TD. Treatment of acanthosis nigricans with tretinoin. Arch Dermatol. 1991;127:1139-40.

41. Higgins SP, Freemark M, Prose NS. Acanthosis nigricans: a practical approach to evaluation and management. Dermatol Online J. 2008;14:2.

42. Adigun C, Pandya A. Improvement of idiopathic acanthosis nigricans with a triple combination depigmenting cream. J Eur Dermatol Venereol. 2009;23:486-7.

43. Blobstein SH. Topical therapy with tretinoin and ammonium lactate for acanthosis nigricans associated with obesity. Cutis. 2003;71:33-4.

44. Sperling LC, SInclair R, Shabrawi-Caelen L. Dermatology. Philadelphia: Elsevier; 2012. p. 1093-8.

45. Gonzalez-Gonzalez JG, Mancillas-Adame LG, Fernandez-Reyes M, Lavalle-Gonzalez FJ, Ocampo-Candiani J. Androgenetic alopecia and insulin resistance in young men. Clin Endocrinol. 2009;71:494-9.

46. Blume-Peytavi U, et al. S1 guideline for diagnostic evaluation in androgenetic alopecia in men, women and adolescents. Br J Dermatol. 2011;164:5-15.

47. Olsen EA, et al. Evaluation and treatment of male and female pattern hair loss. J Am Acad Dermatol. 2005;52:301-11.
48. Severi G, et al. Androgenetic alopecia in men aged 40-69 years: prevalence and risk factors. $\mathrm{Br} \mathrm{J}$ Dermatol. 2003;149:1207-13.

49. Nabaie L, et al. Androgenic alopecia and insulin resistance: are they really related? Clin Exp Dermatol. 2009;34:694-7.

50. Matilainen V, Koskela P, Keinänen-Kiukaanniemi S. Early androgenetic alopecia as a marker of insulin resistance. Lancet. 2000;356:1165-6.

51. Kaliyadan F, Nambiar A, Vijayaraghavan S. Androgenetic alopecia: an update. Indian J Dermatol Venereol Leprol. 2013;79:613-25.

52. Otberg N, Finner AM, Shapiro J. Androgenetic Alopecia. Endocrinol Metab Clin N Am. 2007;36:379-98.

53. Sawaya M, Shalita A. Androgen receptor polymorphisms (CAG repeat lengths) in androgenetic alopecia, hirsutism, and acne. J Cutan Med Surg. 1998;3:9-15.

54. Bakry O, Shoeib MA, El Shafiee M, Hassan A. Androgenetic alopecia, metabolic syndrome, and insulin resistance: is there any association? A case-control study. Indian Dermatol Online J. 2014;5:276-91.

55. Trieu N, Eslick GD. Alopecia and its association with coronary heart disease and cardiovascular risk factors: a meta-analysis. Int J Cardiol. 2014;176:687-95.

56. SInclair R. Male pattern androgenetic alopecia. BMJ. 1998;317:865-9.

57. Su L-H, Chen L-S, Lin S-C, Chen H-H. Association of androgenetic alopecia with mortality from diabetes mellitus and heart disease. JAMA Dermatol. 2013;149:601-6.

58. Tosti A, Torres F. Dermoscopy in the diagnosis of hair and scalp disorders. Actas Dermosifiliogr. 2009;100:114-9.

59. Blumeyer A, et al. Evidence-based (S3) guideline for the treatment of androgenetic alopecia in women and in men. J Dtsch Dermatol Ges. 2011;9:1-57.

60. Cash TF. The psychosocial consequences of androgenetic alopecia: a review of the research literature. Br J Dermatol. 1999;141:398-405.

61. Dumitrescu R, Mehedintu C, Briceag I, Purcarea V, Hudita D. The polycystic ovary syndrome: an update on metabolic and hormonal mechanisms. J Med Life. 2015;8:142-5.

62. Jeffcoate W, Kong M-F. Diabète des femmes à barbe: a classic paper reread. Lancet. 2000;356:1183-5. 
63. Vryonidou A, Paschou S, Muscogiuri G, Orio F, Goulis D. Metabolic Syndrome through the females life cycle. Eur J Endocrinol. 2015;1:153.

64. Poretsky L, Piper B. Insulin resistance, hypersecretion of LH, and a dual-defect hypothesis for the pathogenesis of polycystic ovary syndrome. Obs Gynecol. 1994;84:613-21.

65. Housman E, Reynolds RV. Polycystic ovary syndrome: a review for dermatologists Part I. Diagnosis and manifestations. J Am Acad Dermatol. 2014;71:847-e1.

66. Knochenhauer E, et al. Prevalence of the polycystic ovary syndrome in unselected black and white women of the southeastern United States: a prospective study. J Clin Endocrinol Metab. 1998;83:3078-82.

67. Ferriman D, Gallwey J. Clinical assessment of body hair in women. J Clin Endocrinol Metab. 1961;21:1440-7.

68. Rosenfield RL. Hirsutism. NEJM. 2005;24:2578-88.

69. Claman P. SOGC clinical practice guidelines. Hirsutism: evaluation and treatment. J Obs Gynaecol Can. 2002;24:62-73.
70. Hohl A, Ronsoni MF, Oliveira M. Hirsutism: diagnosis and treatment. Arq Bras Endocrinol Metab. 2014;58:97-107.

71. Azziz R, et al. Criteria for defining polycyctic ovary syndrome as a predominantly hyperandrogenetic syndrome: an androgen excess society guideline. J Clin Endocrinol Metab. 2006;91:4237-45.

72. Melnik BC, John SM, Plewig G. Acne: risk indicator for increased body mass index and insulin resistance. Acta Derm Venereol. 2013;93:644-9.

73. Demir B, et al. Changes in serum desnutrin levels in patients with acne vulgaris. Eur J Dermatol. 2014;24:589-93.

74. Monfrecola G, et al. Mechanistic target of rapamycin (mTOR) expression is increased in acne patients' skin. Exp Dermatol. 2016;25:153-5.

75. Norman RJ, Dewailly D, Legro RS, Hickey TE. Polycystic ovary syndrome. Lancet. 2007;370:685-97.

76. Buzney E, Sheu J, Buzney C, Reynolds R. Polycystic ovary syndrome: A review for dermatologists: Part II. Treatment. J Am Acad Dermatol. 2014;71:859-e1. 